\title{
Temperature Sensor for Road Tunnel Emergencies
}

\author{
Milan Oravec ${ }^{1}$, Michal Gorzás ${ }^{1}$ and Martina Dulebová ${ }^{1 *}$ \\ ${ }^{1}$ Technical university of Kosice, faculty of Mechanical Engineering, Department of Safety and Quality Production, Kosice, Slovakia
}

\begin{abstract}
Fire safety of road tunnels depends on quick identification of a developing fire and its location. Current systems, which are based on the principle of direct temperature sensing, do not identify a fire before its second stage. The paper suggests the possibility of utilizing the principle of the Curie temperature for identification of increased temperatures resulting from a developing fire in road tunnels. The proposed temperature sensor can complement the existing fire protection system for tunnels and increase its effectiveness.
\end{abstract}

Keywords: Curie temperature, temperature sensor, neodymium.

\section{Introduction}

Road and motorway tunnels are specific types of objects in which one dimension prevails in comparison to others. Fire spreads in a characteristic way in these constructions, therefore, its quick detection is necessary. There are several important factors influencing fire in objects of such shape.

The most serious problem of road tunnels is the amount of freight transport, which in some tunnels reaches $40 \%$ of all vehicular traffic [1], whereas a value exceeding $15 \%$ is considered to pose an increased risk [2]

Only in the European Union alone, transport of dangerous loads exceeds 110 billion tonne-kilometres out of which $58 \%$ is transported by road, $25 \%$ by rail and $17 \%$ by water [3].

\section{Current state}

The production of statistics on accidents in existing and newly-built tunnels increases the possibilities of accident prediction and enables us to create measures to minimize risks. Table 1 shows the maximum temperatures and heat flows of selected fire tests in road tunnels. The presented values indicate that fire of freight transport vehicles has a higher impact that fire of passenger cars.

The importance of searching for new and secondary fire detection and signalization systems is evident form Figure 1, which depicts the percentual share of system failures in a selected road tunnel [2].

\subsection{Identification of fire in road tunnels}

Commonly used methods of temperature measurement include contact and radiation thermometry. In the contact measurement, however, the thermometer influences the temperature of the object to be measured. Besides, it requires some time before the thermometer sensor fully reacts to the temperature of the object. The process can be expressed by a first order differential equation. The time constant can be determined from the thermal capacity of the sensor and the thermal resistance between the sensor and the object being measured. The second method is based on the measurement of (thermal) radiation of the measured object. The radiation is focused onto a temperature sensitive detector, which 
Tab. 1: Results of fire testing of passenger and freight transport vehicles in road tunnels.

\begin{tabular}{|c|c|c|c|}
\hline Type of fuel, test series, test number, $v_{p}$ longitudinal air velocity, $A=$ area & $\begin{array}{l}\text { Maximum } \\
\text { HRR [MW] }\end{array}$ & $\begin{array}{l}\text { Maximum } \\
\text { temperature } \\
\text { reached }\left[{ }^{\circ} \mathrm{C}\right]\end{array}$ & Reference \\
\hline \multicolumn{4}{|l|}{ passenger cars } \\
\hline $\begin{array}{l}\text { Renault Espace J11- II manufactured in 1988, EUREKA 499, } v_{p}=0,4 \\
\qquad m \cdot s^{-1}, A=25-35 m^{2}\end{array}$ & 6 & 480 & $\begin{array}{l}\text { EUREKA } \\
\text { report [6] }\end{array}$ \\
\hline $\begin{array}{l}\text { Opel Kadett 1990, 2nd Benelux test, } \\
\text { Test } 6 \text { and } 7, v_{p}=0 \text { a } 6 \mathrm{~m}^{-1} \mathrm{~s}^{-1} \mathrm{~A}=50 \mathrm{~m}^{2}\end{array}$ & 4,$8 ; 4,7$ & $210 ; 110$ & Lemair et al [7] \\
\hline \multicolumn{4}{|l|}{ freight transport vehicles } \\
\hline $\begin{array}{l}\text { Trailer loaded with } 10.9 \text { tonnes of wooden (82\%) and plastic (18\%) } \\
\text { pallets, Runehamar test, } v_{p}=3 \mathrm{~m} \cdot \mathrm{s}^{-1}, \mathrm{~A}=50 \mathrm{~m}^{2}\end{array}$ & 203 & 1,365 & $\begin{array}{l}\text { Lönnermark and } \\
\text { Ingason [8] }\end{array}$ \\
\hline $\begin{array}{l}\text { Trailer loaded with } 8.5 \text { tonnes of furniture and tyres, Runehamar test, } \\
\qquad v_{p}=3 \mathrm{~m} \cdot \mathrm{s}^{-1}, A=50 \mathrm{~m}^{2}\end{array}$ & 125 & 1,281 & $\begin{array}{l}\text { Lönnermark and } \\
\text { Ingason [8] }\end{array}$ \\
\hline $\begin{array}{l}\text { Trailer model loaded with } 3.1 \text { tonnes of cardboard boxes containing } \\
\text { plastic cups (19\%), Runehamar test, } v_{p}=3 \mathrm{~m}^{-1} \mathrm{~s}^{-1}, \mathrm{~A}=50 \mathrm{~m}^{2}\end{array}$ & 70 & 1,305 & $\begin{array}{l}\text { Lönnermark and } \\
\text { Ingason [8] }\end{array}$ \\
\hline
\end{tabular}

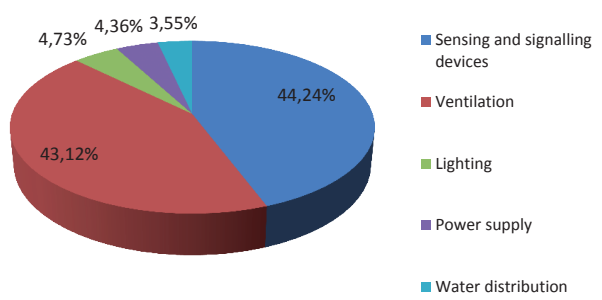

Fig. 1: System failures in a selected road tunnel.

facilitates measurement of an object's temperature from its radiation. When this method is employed, the thermal load is negligible.

In general, thermometers are based on several basic principles [4]:

1) Thermal expansion of solid, liquid or gas thermometric substances. Thermal expansion of a thermometric substance or the difference between thermal expansions of two substances then indicates the temperature. Change in the volume of the thermometric substance is measured at constant pressure.

2) Change in the electrical properties of the sensor depending on temperature changes. It uses:

a) the dependence of electrical resistance of conductors and semiconductors on temperature,

b) the generation of thermoelectric voltage in the circuit formed by two different metallic conductors whose ends are joined and exposed to two different temperatures (Seebeck effect),

3) Sensing the total radiance energy. Solid and liquid substances emit thermal radiation $\mathrm{T}>0 \mathrm{~K}$ at any temperature. Thermal dependence of the radiation measured by thermal detectors is used to determine the temperature.

4) Utilization of spectral radiation of the object being measured. An object's spectral radiance grows with increased temperature of the object.

\subsection{Magnetic and thermal properties of neodymium magnets}

Neodymium magnets are currently the most powerful magnets with excellent magnetic properties, such as remanence and energy product [9]. Neodymium magnets are based on rare earth elements (lanthanides), their main components are iron (Fe), neodymium ( $\mathrm{Nd}$ ) and boron (B). Other elements are added into the final alloy, especially cobalt (Co) and dysprosium (Dy), to improve magnetic parameters (remanence, coercivity) and thermal stability (maximum working temperature) of the alloy. The working temperature of neodymium magnets is between +80 and $+240^{\circ} \mathrm{C}$, depending on material grade. Neodymium magnets have excellent resistance to external magnetic fields and in normal conditions retain permanent magnetic properties.

\section{Testing the influence of temperature on the magnetic properties of neodymium magnets}

Prior to testing, it is important to mention the Curie-Weiss law, which says that magnetic susceptibility $\chi$ of paramagnetic material depends on its temperature, according to equation: 
$\chi=\frac{C}{T-T_{c}}$

$\chi$ - magnetic susceptibility

C - Curie constant

$\mathrm{T}$ - temperature $\left[{ }^{\circ} \mathrm{C}\right]$

$\mathrm{T}_{\mathrm{c}}$ - Curie temperature $\left[{ }^{\circ} \mathrm{C}\right]$

Depending on the value of magnetic susceptibility, materials can be classified as:
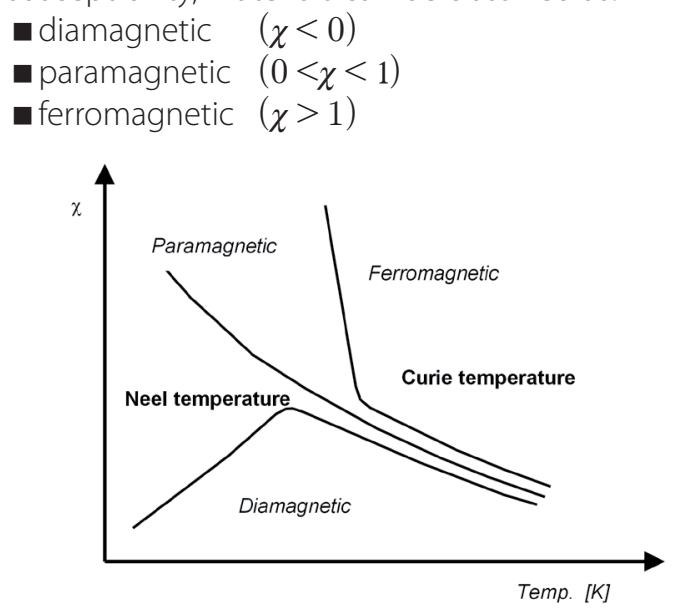

Fig. 2: Decrease in magnetization of ferromagnetic materials depending on temperature.

The test was conducted on an anisotropic neodymium block magnetized through thickness $\mathrm{H}$ (axially) with maximum working temperature of $+80^{\circ} \mathrm{C}$. The coercive force of the magnet specified by the manufacturer is determined at room temperature $\left(20^{\circ} \mathrm{C}\right)$ in contact with a polished plate made of mild steel with a thickness of $10 \mathrm{~mm}$ by pulling the magnet vertically from the surface $(1 \mathrm{~kg} \approx 10 \mathrm{~N})$ [10]. Table 2 shows the characteristic parameters of neodymium magnets being tested.

The aim of the experiment was to verify the influence of temperature on the coercive force of a neodymium magnet. Individual test samples were gradually exposed to various temperatures ranging from +20 to $+350^{\circ} \mathrm{C}$ and their coercive force was measured by a pull-force gauge. The measurement was performed using a test stand pictured in
Figure 3, where $\mathrm{N}$ is the neodymium magnet being measured and $\mathrm{D}$ is the contact plate.

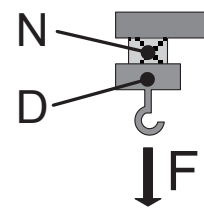

Fig. 3: Measurement of coercive force of neodymium magnets.

The force measured by a pull-force gauge is the sum of coercive and gravitational force, expressed as:

$F=F_{\text {coerc }}+G$

$F=F_{\text {coerc }}+\left(m_{N}+m_{D}\right) g$

$\mathrm{F}$ - force $[\mathrm{N}]$

Fcoerc - coercive force [N]

$\mathrm{G}$ - gravitational force $[\mathrm{N}]$

$\mathrm{mN}$ - neodymium magnet weight [kg]

$\mathrm{mD}$ - gripping fixture weight $[\mathrm{kg}]$

$\mathrm{g}$ - gravitational acceleration $\left[\mathrm{m} / \mathrm{s}^{2}\right]$

It is apparent from the experiment that the coercive force of the neodymium sample decreases in proportion to the increased temperature. When the material temperature increases, each atom oscillates around its equilibrium position in the crystal lattice. The oscillation disrupts the alignment of magnetic moments'spins. This implies that with increasing temperature of ferromagnetic material its magnetization decreases, as shown in Fig. 2.

The decline continues until the temperature reaches the Tc value, known as the Curie temperature, when parallel (collinear) orientation of magnetic moments is lost and they align randomly. Above the Curie temperature, the

Tab. 2: Magnetic and mechanical properties of neodymium magnets used in the test.

\begin{tabular}{|c|c|c|c|c|c|c|c|}
\hline $\begin{array}{l}\text { Dimensions } \\
\text { [mm] }\end{array}$ & Weight [g] & $\begin{array}{l}\text { Coercive } \\
\text { force [N] }\end{array}$ & Coating & $\begin{array}{c}\text { Recommended } \\
\text { magnetizing field } \\
\text { [kA/m] }\end{array}$ & $\begin{array}{c}\text { Curie } \\
\left.\text { Temperature [ }{ }^{\circ} \mathbf{C}\right]\end{array}$ & Density $\left[\mathrm{g} / \mathrm{cm}^{3}\right]$ & Hardness [Hv] \\
\hline $4 \times 4 \times 2$ & 0.24 & 4.2 & $\mathrm{Ni}$ & 2400 & $310-340$ & 7.5 & 570 \\
\hline
\end{tabular}


magnetic dipole moments are oriented at random, chaotically, without a preferred direction. After the ferromagnetic cools bellow the Curie temperature, its moments spontaneously align in one direction. It is a spontaneous distortion of symmetry, because the non-magnetic phase has a higher symmetry (all directions are equivalent and the field is isotropic), than magnetic (with a preferred direction of spontaneous magnetization).

Figure 4 shows the dependency of the coercive force on respective temperatures affecting the tested neodymium sample. The change in the magnetic properties of samples caused by the increased temperatures is permanent.

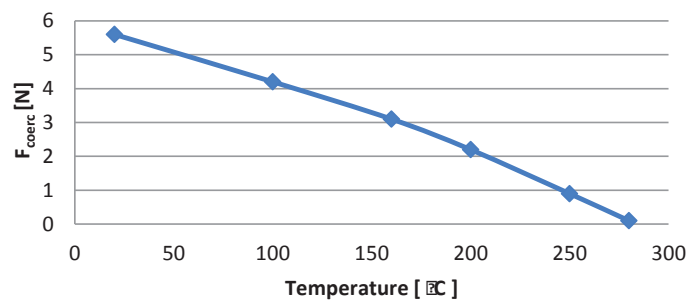

Fig. 4: Measured dependency of coercive force on the temperature of the tested neodymium sample.

After verifying the magnetic properties of neodymium magnets, a solution based on the Curie temperature and Earth's gravitational field was proposed.

\section{Design concept of the temperature sensor based on neodymium magnet}

The change in the magnetic properties of neodymium magnets after reaching the Curie temperature can be utilized in the design of the proposed sensor. The sensor detects the increased temperature and reacts to it by a step change, i.e., depending on the sensor structure, it will either switch the electric circuit on (Figure 5a) or off (Figure $5 b)$.

The condition required for switching the electric circuit on/off is:

$G>F_{\text {coerc }}$

\section{G - gravitational force [N]}

Fcoerc-coercive force [N]

This change in the state is permanent, which means the sensor has a memory effect. The neodymium magnet of the switch has to be replaced in order to restore the function of the sensor. The value of the temperature to be detected is determined by the material properties of the neodymium magnet being used. Should the detectors of increased temperatures be used in large objects and line constructions, such as tunnels, sensors containing a higher number of neodymium magnets can be constructed.

\section{Conclusions}

The paper suggests the possibility of utilizing the principle of the Curie temperature for identification of changing temperatures caused by fire in road tunnels. The proposed temperature sensor is based on the fact that the magnetic properties of neodymium magnets change after the Curie temperature has been reached. The sensor reacts to the increased temperature by a step change; i.e., depending on the sensor structure, it either switches the electric circuit on or off. This change in the state of the sensor is permanent, hence bringing a memory effect.

(a)
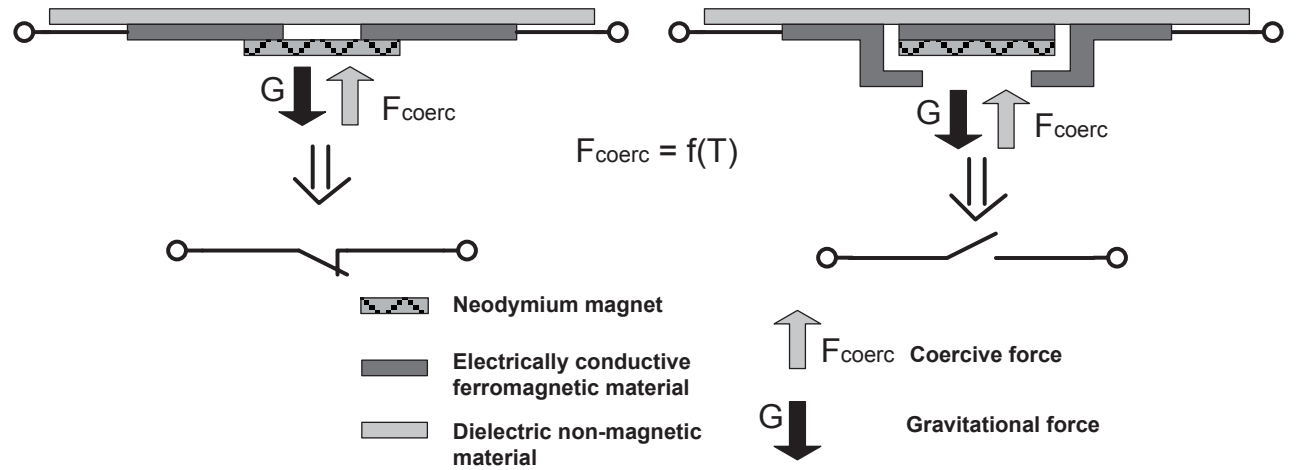

Fig. 3: Design concept of the magnetic temperature sensor a) when the electric circuit is on, b) when the electric circuit is off. 


\section{Acknowledgments}

This contribution is the result of the project VEGA no. 1/0150/15 Development of methods of implementation and verification of integrated safety systems, machine, machinery, systems and industrial technologies.

This contribution is the result of the Project implementation: University Science Park TECHNICOM for Innovation Applications Supported by Knowledge Technology, ITMS: 26220220182, supported by the Research \& Development Operational Programme funded by the ERD.

\section{References:}

[1] Glatz, J. (2007). Havarijné plánovanie cestných tunelov. PhD thesis, KBaKP, TUKE Košice, p.

[2] Rusnák, O. (2011). Medzistropná doska - rizikový prvok cestných tunelov. PhD thesis, KBaKP, TUKE Košice, Košice, 123 p.

[3] Európska komisia. Transeurópske siete (TEN), from http:// ec.europa.eu/transport/road_safety/ topics/infrastructure/ trans-european_networks/index_sk.htm (14.05.2016).

[4] Riegen, P., Halaj, M., Kureková, E. Meranie teploty, Modul M08, from http://www.kam.sjf.stuba.sk/katedra/publikacie/ leonardo/ucebnica/08s.pdf. (13.05.2016).

[5] Tunel, Časopis českého tunelářského komitétu a slovenskej tunelárskej asociácie ITA/AITES. (2008). 17, 2, 74, from http:// www.ita-aites.cz/files/tunel/komplet/tunel_2_08.pdf6. (02.06.2016).

[6] Fires in Transport Tunnels, Report on full-scale tests. (1995). EUREKA-Project EU499;Firetun, Studiengesellschaft Stahlanwendung elV. D-40213 Dusseldorf.

[7] Lemair, A., Kenyon,Y.M. (2002). TNO Metingen Beneluxtunnel Meetrapport, TNO-Rapport, CVB-R05572.

[8] Lönnermark, A., Ingason, H. (2003). Large Scale Fire Tests in the Runehamar tunnel - Gas temperature and Radiation, Proceedings of the International Seminar on Catastrophic Tunnel Fires, Borås, Sweden.

[9] SELOS. Neodymy, from http://www.magnety.sk/magneticke-materialy/neodymy (08.06.2016).

[10] SELOS.Neodym blok, anizotrop, from http://www.magnety. sk/neodym-blok-anizotrop (10.06.2016).

\section{Biographical notes}

prof. Ing. Milan Oravec, PhD. (born in 1960) works at the Department of Safety and Quality of Production SjF TU in Košice. The issue of risk assessment deals with the creation of the Department of the Technical University in Košice (1990). In 1992, he defended his work in the field of oscillation. In 1995, he passed habilitation in the field of production quality and safety of technical systems. In 2009, he defended his professorship in the field of security and fire protection at VŠB - Technical University of Ostrava. He is a member of three scientific councils in the (zech Republic, two in the Slovak Republic, and participates on the editorial boards of several journals. In recent years, he addressed the issue of methods and procedures development in the field of prevention of industrial accidents, safety in road tunnels, and security line structures. Currently, he solves the development of methods for the assessment of integral risk of critical infrastructure asymmetric threats.

Ing. Michal Gorzás, PhD. (born in 1977) graduated on the Mechanical Engineering Faculty, TU Košice in 2001 and obtained PhD in Mechatronics. At present he is an lecturer on the Department of Safety and Quality of production, Faculty of Mechanical Engineering, Technical University in Košice. He is author more than 60 publications in journals and conference proceedings at Slovakia and abroad. His research interest includes precision mechanics, mechatronics and information safety.

Ing. Martina Dulebová (born in 1989) graduated on the Mechanical Engineering Faculty, TU Košice in 2014. She is an internal PhD. student on the Department on Safety and Quality of Production, Faculty of Mechanical Engineering, Technical University in Košice. Her research and dissertation work is about Prediction of acoustic risks as a part of the safety analysis in the context of integrated safety. 